\title{
Insights into a hotspot in the Brasiliensis subcomplex (Hemiptera, Triatominae) by analysis of D2 domain of the nuclear gene $28 \mathrm{~S}$
}

\author{
A.L. Guerra ${ }^{1}$, K.C.C. Alevi ${ }^{1}$, C.A. Banho ${ }^{2}$, J. Oliveira ${ }^{3}$, J.A. Rosa ${ }^{3}$ and \\ M.T.V. Azeredo-Oliveira ${ }^{1}$ \\ 'Laboratório de Biologia Celular, Departamento de Biologia, \\ Instituto de Biociências, Letras e Ciências Exatas, \\ Universidade Estadual Paulista "Júlio de Mesquita Filho", \\ São José do Rio Preto, SP, Brasil \\ ${ }^{2}$ Laboratório de Citogenética e Molecular de Insetos, \\ Departamento de Biologia, Instituto de Biociências, \\ Letras e Ciências Exatas, Universidade Estadual Paulista "Júlio de Mesquita Filho", \\ São José do Rio Preto, SP, Brasil \\ ${ }^{3}$ Laboratório de Parasitologia, Departamento de Ciências Biológicas, \\ Faculdade de Ciências Farmacêuticas, \\ Universidade Estadual Paulista "Júlio de Mesquita Filho", Araraquara, SP, Brasil \\ Corresponding author: K.C.C. Alevi \\ E-mail: kaiochaboli@hotmail.com \\ Genet. Mol. Res. 15 (1): gmr.15017449 \\ Received August 13, 2015 \\ Accepted November 13, 2015 \\ Published March 24, 2016 \\ DOI http://dx.doi.org/10.4238/gmr.15017449
}

ABSTRACT. The Brasiliensis subcomplex is a monophyletic group formed by the species Triatoma brasiliensis brasiliensis, T. b. macromelasoma, $T$. juazeirensis, T. melanica, and T. sherlocki. However, using cytogenetic data and experimental hybrid crosses, $T$. lenti and T. petrochiae were also grouped into this subcomplex. This study aims to analyze the properties of hotspot in the D2 domain of the nuclear gene 28S in all species of the Brasiliensis subcomplex as well as $T$. lenti and $T$. petrochiae. These species show two transversions at position $385(\mathrm{G} \leftrightarrow \mathrm{C}$ and $\mathrm{T} \leftrightarrow \mathrm{G})$. We suggest that this mutation in haplotype 4 may be an initial molecular tool that supports the relationship 
of these species with the subcomplex. In addition to the transversion at haplotype 4 , these species, aside from $T$. melanica, also possess a transversion at position $385(\mathrm{G} \leftrightarrow \mathrm{T})$ in haplotype 1 . Thus, we describe the hotspot mutations of the D2 domain of the nuclear gene $28 \mathrm{~S}$ for species in Brasiliensis subcomplex as follows: three transversions are present at position 385 of haplotypes 1 and 4 , which are shared by members of the subcomplex as well as T. lenti and T. petrochiae. These transversions may be considered a synapomorphy between these species. However, we emphasize that new phylogenetic studies should be conducted to evaluate whether T. lenti and $T$. petrochiae are truly members of the Brasiliensis subcomplex.

Key words: Triatoma lenti; Triatoma petrochiae; Hotspot

\section{INTRODUCTION}

The Triatominae subfamily consists of 150 species that are divided into 18 genera (Alevi et al., 2015). These species can also be grouped into complexes and specific subcomplexes (Lent and Wygodzinsky, 1979; Carcavallo et al., 2000; Schofield and Galvão, 2009). Although complexes and subcomplexes are not valid according to the International Code of Zoological Nomenclature (Carcavallo et al., 2000) they should be considered monophyletic groups (Justi et al., 2014).

Schofield and Galvão (2009) mainly used morphological characteristics and geographical distribution to group nine species in the Brasiliensis subcomplex: Triatoma brasiliensis Neiva, 1911; T. juazeirensis Costa \& Felix, 2007; T. melanica Costa, Argolo \& Felix, 2006; T. melanocephala Neiva \& Pinto, 1923; T. petrochiae Pinto \& Barreto, 1925; T. lenti Sherlock \& Serafim, 1967; T. sherlocki Papa, Jurberg, Carcavallo, Cerqueira \& Barata, 2002; T. tibiamaculata Pinto, 1926; and T. vitticeps Stal, 1859. However, T. melanocephala, T. tibiamaculata and T. vitticeps were excluded from this subcomplex based on cytogenetic (Alevi et al., 2012a, 2013a, 2014a,b) and molecular analyses (Gardim et al., 2014).

All phylogenetic reconstructions of the Brasiliensis subcomplex were conducted with mitochondrial (Cyt b,16S, COI and COII) and nuclear (18S and 28S) genes. Brasiliensis subcomplex is a monophyletic group formed by the species T. b. brasiliensis, T. b. macromelasoma, T. juazeirensis, T. melanica, and T. sherlocki (Monteiro et al., 2004; Mendonça et al., 2009; Gardim et al., 2014; Justi et al., 2014). However, we emphasize that T. lenti and T. petrochiae were not used in any of the phylogenetic analyses described above (perhaps due to difficulties in sample collection). Cytogenetic data (Alevi et al., 2012b, 2013b, 2014a) and experimental hybrid crosses (Mendonça et al., 2014) suggest that $T$. lenti can be considered as a member of this subcomplex.

Monteiro et al. (2004) found independent mutations on the same sites of the Cyt b gene during phylogenetic reconstruction. These sites are high frequency homoplasic sites known as hotspots. Mutation hotspots often reflect a specific mechanism of generating mutations at a particular site and/or unusual properties of a phenotypic selection (Rogozin and Pavlov, 2003).

Thus, this study aims to analyze hotspots in the D2 domain of the nuclear gene 28S in all species of the Brasiliensis subcomplex (T. b. brasiliensis, T. b. macromelasoma, T. juazeirensis, $T$. melanica, and T. sherlocki), as well as T. lenti and T. petrochiae.

\section{MATERIAL AND METHODS}

Seven adult specimens of each species belonging to the Brasiliensis subcomplex (except 
for T. melanica, where only two specimens could be collected due to difficulties with sample collection) and T. infestans (as an outgroup), were obtained from the "Insectary of Triatominae", Faculdade de Ciências Farmacêuticas (FCFAR/UNESP), Campus of Araraquara, São Paulo, Brazil.

These triatomines were dissected, and the legs were used for extraction of genetic material using the DNeasy Blood and Tissue Kit (QIAGEN) according to the manufacturer instructions. Amplification of variable region D2 in the $28 \mathrm{~S}$ gene ( $\mathrm{rDNA})$ was performed via PCR as previously described by Porter and Collins (1996). The primers used were as follows: forward sequence: 5'-GCGAGTCGTGTTGCTTGATAGTGCAG-3' and reverse sequence: 5'-TTGGTCCGTGTTTCAAGACGGG-3'. The cycling parameters are as follows: an initial cycle at $95^{\circ} \mathrm{C}$ for $2 \mathrm{~min} ; 40$ cycles of denaturation $\left(95^{\circ} \mathrm{C}, 30 \mathrm{~s}\right)$, annealing $\left(68^{\circ} \mathrm{C}, 30 \mathrm{~s}\right)$, and extension $\left(72^{\circ} \mathrm{C}\right.$, $1 \mathrm{~min}$ ); and one cycle at $72^{\circ} \mathrm{C}$ for $5 \mathrm{~min}$. Following electrophoresis, the amplified fragments were purified using the GFX PCR DNA \& Gel Band kit (GE Healthcare and Life Technology) according to the manufacturer instructions.

Purified PCR products were subjected to direct sequencing. Samples were sent to the Research Center on the Human Genome and Stem Cells, USP/São Paulo, Brazil. Sequences of all individuals were analyzed by the BioEdit software 7.0.5, and a consensus sequence was obtained for each DNA segment. The sequences were aligned using ClustalW editor.

We constructed a haplotype network using the TCS 1.21 software (Clement et al., 2000) based on the statistical parsimony method (Templeton et al., 1992). Reticulations were resolved according to common theoretical predictions about network structures (Crandall and Templeton, 1993; Posada and Crandall, 2001).

\section{RESULTS}

All species analyzed, except for $T$. infestans, presented hotspot mutations in haplotype 4, which were characterized as two transversions at position $385(\mathrm{G} \leftrightarrow \mathrm{C}$ and $\mathrm{T} \leftrightarrow \mathrm{G})$ (Figure 1). With the exception of $T$. melanica, all species showed transversion at position $385(\mathrm{G} \leftrightarrow \mathrm{T})$ of haplotype 1. In addition to the mutations described above, $T$. brasiliensis showed a transition in haplotype 2 , and a transition at position $495(\mathrm{C} \leftrightarrow \mathrm{T})$ was found in the $T$. infestans outgroup (Figure 1).

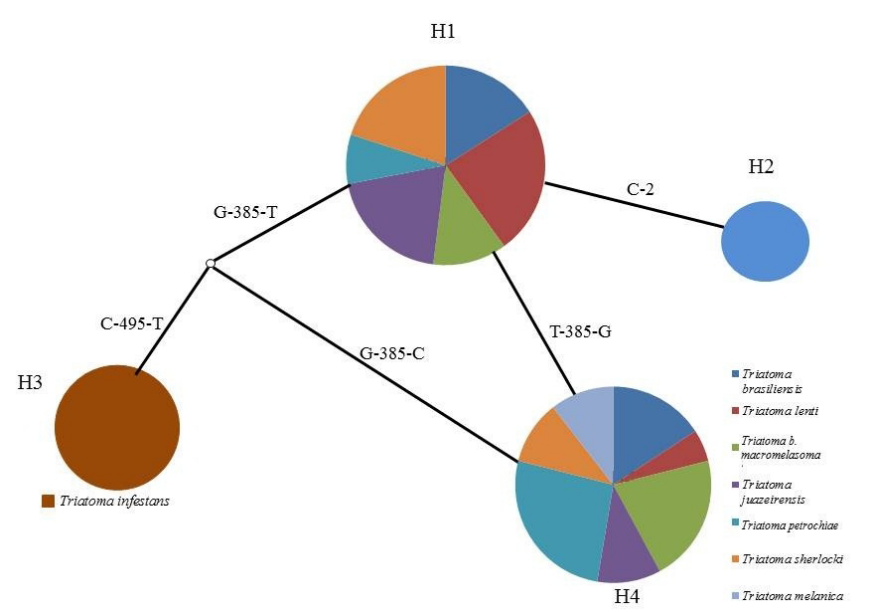

Figure 1. Parsimony haplotype network showing hotspot mutations in species of the subcomplex Brasiliensis, with Triatoma infestans as the outgroup. 


\section{DISCUSSION}

The D2 domain of the nuclear gene 28S is frequently used in phylogenetic studies in the Rhodniini tribe (Monteiro et al., 2000, 2003; Díaz et al., 2014). In the Rhodniini tribe, this gene is more conserved as compared with other genes, containing only $9 \%$ variable sites (Monteiro et al., 2000). Díaz et al. (2014) observed that the D2 domain of the nuclear gene $28 S$ contained only 12 variable sites in the pallescens group. Monteiro et al. (2003) by means of D2 domain of the nuclear gene $28 \mathrm{~S}$ corroborates the paraphilia of $R$. robustus because $R$. prolixus and $R$. robustus from the Orinoco region share a derived $\mathrm{C}$ in position 360 .

For a long time, the species of the Brasiliensis subcomplex were considered to be chromatic variants of T. brasiliensis (Costa et al., 1998). Costa et al. (2006) elevated the specific status of T. b. melanica to T. melanica. Costa and Felix (2007) described T. juazeirensis based on the T. brasiliensis population in Juazeiro/Bahia. Mendonça et al. (2009) grouped T. sherlocki into the Brasiliensis subcomplex based on phylogenetic analyses with mitochondrial genes (16S and Cyt b). Costa et al. (2013) revalidated and re-described the subspecies T. b. macromelanosoma based on melanin forms of $T$. brasiliensis encountered at housing (Galvão, 1955).

All species of the Brasiliensis subcomplex have cytogenetic synapomorphies: 20 autosomes plus two sex chromosomes ( $X Y$ in males and $X X$ in females), C-blocks in one or both chromosomal ends in all autosomal pairs, a large chromocenter made up of both sex chromosomes plus two autosomal pairs, and multiple C-dots spread in the nucleus during early meiotic prophase (Panzera et al., 2000; Alevi et al., 2013a, 2014a). T. vitticeps, T. melanocephala, and T. tibiamaculata, which were excluded from this subcomplex, have been found to have multiple sex systems and different C-heterochromatin patterns (Panzera et al., 2010; Alevi et al., 2012a, 2013a, 2014b).

Hotspot analyses showed that all species belonging to the Brasiliensis subcomplex as well as $T$. lenti and $T$. petrochiae have two transversions at position 385 ( $\mathrm{G} \leftrightarrow \mathrm{C}$ and $\mathrm{T} \leftrightarrow \mathrm{G}$ ). Considering that $T$. lenti and T. petrochiae have the same cytogenetic characteristics described for the Brasiliensis subcomplex (Panzera et al., 2000; Alevi et al, 2012b, 2013b, 2014a), it is possible that this mutation in haplotype 4 may be an initial molecular tool that supports inclusion of these species within the subcomplex.

In addition to transversion in haplotype 4, all species except for $T$. melanica also demonstrated transversion at position $385(\mathrm{G} \leftrightarrow \mathrm{T})$ in haplotype 1 . Since $T$. melanica is the most evolutionarily differentiated species within the subcomplex, it may have genetic incompatibility and provide unviable hybrids with other members of the Brasiliensis subcomplex (Costa et al., 2006). It is possible that this hotspot can also be a defining feature of the species within this subcomplex.

In this study, we have illustrated hotspot mutations in the D2 domain of the nuclear gene 28S for species in the Brasiliensis subcomplex, and suggest that three transversions at position 385 of haplotypes 1 and 4 are shared by members of the subcomplex as well as $T$. lenti and T. petrochiae. However, we emphasize that new phylogenetic studies should be conducted to evaluate whether T. lenti and T. petrochiae truly are members of the Brasiliensis subcomplex.

\section{Conflicts of interest}

The authors declare no conflict of interest. 


\section{ACKNOWLEDGMENTS}

We thank Dr. Carlos Eduardo Almeida for the assistance in constructing a haplotype network and the useful comments. We especially thank Dr. Claudia Carareto for support in the molecular analyses. Research supported by Conselho Nacional de Desenvolvimento Científico e Tecnológico (CNPq), and Coordenação de Aperfeiçoamento de Pessoal de Nível Superior (CAPES).

\section{REFERENCES}

Alevi KC, Mendonça PP, Pereira NP, Rosa JA, et al. (2012a). Karyotype of Triatoma melanocephala Neiva and Pinto (1923). Does this species fit in the Brasiliensis subcomplex? Infect. Genet. Evol. 12: 1652-1653.http://dx.doi.org/10.1016/j. meegid.2012.06.011

Alevi KC, Mendonça PP, Succi M, Pereira NP, et al. (2012b). Karyotype and spermatogenesis in Triatoma lenti (Hemiptera: Triatominae), a potential Chagas vector. Genet. Mol. Res. 11: 4278-4284.http://dx.doi.org/10.4238/2012.December.17.3

Alevi KC, Mendonça PP, Pereira NP, Rosa JA, et al. (2013a). Spermatogenesis in Triatoma melanocephala (Hemiptera: Triatominae). Genet. Mol. Res. 12: 4944-4947.http://dx.doi.org/10.4238/2013.October.24.5

Alevi KCC, Mendonça PP, Pereira NP, Guerra AL, et al. (2013b). Distribution of constitutive heterochromatin in two species of triatomines: Triatoma lenti Sherlock and Serafim (1967) and Triatoma sherlocki Papa, Jurberg, Carcavallo, Cerqueira \& Barata (2002). Infect. Genet. Evol. 13: 301-303.http://dx.doi.org/10.1016/j.meegid.2012.11.011

Alevi KC, Rosa JA and Azeredo-Oliveira MTV (2014a). Cytotaxonomy of the Brasiliensis subcomplex and the Triatoma brasiliensis complex (Hemiptera: Reduviidae: Triatominae). Zootaxa 3838: 583-589.http://dx.doi.org/10.11646/ zootaxa.3838.5.7

Alevi KC, Rosa JA and Azeredo-Oliveira MTV (2014b). Distribution of constitutive heterochromatin in Triatoma melanocephala (Hemiptera, Triatominae). Genet. Mol. Res. 13: 7899-7903.http://dx.doi.org/10.4238/2014.September.29.2

Alevi KC, Moreira FFF, Jurberg J and Azeredo-Oliveira MTV (2015). Description of diploid chromosome set of Triatoma pintodiasi (Hemiptera, Triatominae). Genet. Mol. Res., in press. http://dx.doi.org/10.4238/2015.February.6.14

Carcavallo RU, Jurberg J, Lent H, Noireau F, et al. (2000). Phylogeny of the Triatominae (Hemiptera: Reduviidae). Proposals for taxonomic arrangements. Entomol. Vect. 7: 1-99.

Clement M, Posada D and Crandall KA (2000). TCS: a computer program to estimate gene genealogies. Mol. Ecol. 9: 16571659.http://dx.doi.org/10.1046/j.1365-294x.2000.01020.x

Costa J and Felix M (2007). Triatoma juazeirensis sp. nov. from the state of Bahia, Northeastern Brazil (Hemiptera: Reduviidae: Triatominae). Mem. Inst. Oswaldo Cruz 102: 87-90.http://dx.doi.org/10.1590/S0074-02762007000100015

Costa J, de Almeida JR, Britto C, Duarte R, et al. (1998). Ecotopes, natural infection and trophic resources of Triatoma brasiliensis (Hemiptera, Reduviidae, Triatominae). Mem. Inst. Oswaldo Cruz 93: 7-13.http://dx.doi.org/10.1590/S0074$\underline{02761998000100002}$

Costa J, Argolo AM and Felix M (2006). Redescription of Triatoma melanica Neiva \& Lent, 1941, new status (Hemiptera: Reduviidae: Triatominae). Zootaxa 1385: 47-52.

Costa J, Correia NC, Neiva VL, Gonçalves TC, et al. (2013). Revalidation and redescription of Triatoma brasiliensis macromelasoma Galvão, 1956 and an identification key for the Triatoma brasiliensis complex (Hemiptera: Reduviidae: Triatominae). Mem. Inst. Oswaldo Cruz 108: 785-789.http://dx.doi.org/10.1590/0074-0276108062013016

Crandall KA and Templeton AR (1993). Empirical tests of some predictions from coalescent theory with applications to intraspecific phylogeny reconstruction. Genetics 134: 959-969.

Díaz S, Panzera F, Jaramillo-O N, Pérez R, et al. (2014). Genetic, cytogenetic and morphological trends in the evolution of the Rhodnius (Triatominae: Rhodniini) trans-Andean group. PLoS One 9: e87493.http://dx.doi.org/10.1371/journal. pone.0087493

Galvão AB (1955). Triatoma brasiliensis macromelasoma n. subsp. (Reduviidae, Hemiptera). Rev. Bras. Malariol. Doencas Trop. 7: 455-457.

Gardim S, Almeida CE, Takiya DM, Oliveira J, et al. (2014). Multiple mitochondrial genes of some sylvatic Brazilian Triatoma: non-monophyly of the $T$. brasiliensis subcomplex and the need for a generic revision in the Triatomini. Infect. Genet. Evol. 23: 74-79.http://dx.doi.org/10.1016/j.meegid.2014.01.024

Justi SA, Russo CA, Mallet JR, Obara MT, et al. (2014). Molecular phylogeny of Triatomini (Hemiptera: Reduviidae: Triatominae). Parasit. Vectors 7: 149.http://dx.doi.org/10.1186/1756-3305-7-149 
Lent $\mathrm{H}$ and Wygodzinsky P (1979). Revision of the Triatominae (Hemiptera, Reduviidae), and their significance as vectors of Chagas's disease. Bull. Am. Mus. Nat. Hist. 163: 123-520.

Mendonça VJ, da Silva MT, de Araújo RF, Júnior JM, et al. (2009). Phylogeny of Triatoma sherlocki (Hemiptera: Reduviidae: Triatominae) inferred from two mitochondrial genes suggests its location within the Triatoma brasiliensis complex. Am. J. Trop. Med. Hyg. 81: 858-864.http://dx.doi.org/10.4269/aitmh.2009.08-0664

Mendonça VJ, Alevi KCC, Medeiros LMO, Nascimento JD, et al. (2014). Cytogenetic and morphologic approaches of hybrids from experimental crosses between Triatoma lenti Sherlock \& Serafim, 1967 and T. sherlocki Papa et al., 2002 (Hemiptera: Reduviidae). Infect.Gen. Evol. 26: 123-131. http://dx.doi.org/10.1016/j.meegid.2014.05.015

Monteiro FA, Wesson DM, Dotson EM, Schofield CJ, et al. (2000). Phylogeny and molecular taxonomy of the Rhodniini derived from mitochondrial and nuclear DNA sequences. Am. J. Trop. Med. Hyg. 62: 460-465.

Monteiro FA, Barrett TV, Fitzpatrick S, Cordon-Rosales C, et al. (2003). Molecular phylogeography of the Amazonian Chagas disease vectors Rhodnius prolixus and R. robustus. Mol. Ecol. 12: 997-1006.http://dx.doi.org/10.1046/j.1365294X.2003.01802.x

Monteiro FA, Donnelly MJ, Beard CB and Costa J (2004). Nested clade and phylogeographic analyses of the Chagas disease vector Triatoma brasiliensis in Northeast Brazil. Mol. Phylogenet. Evol. 32: 46-56.http://dx.doi.org/10.1016/j. ympev.2003.12.011

Panzera F, Pérez R, Nicolini P, Hornos S, et al. (2000). Chromosome homogeneity in populations of Triatoma brasiliensis Neiva 1911 (Hemiptera - Reduviidae - Triatominae). Cad. Saude Publica 16 (Suppl 2): 83-88.http://dx.doi.org/10.1590/ $\underline{\text { S0102-311X2000000800009 }}$

Panzera F, Perez R, Panzera Y, Ferrandis I, et al. (2010). Cytogenetics and genome evolution in the subfamily Triatominae (Hemiptera, Reduviidae). Cytogenet. Genome Res. 128: 77-87.

Porter $\mathrm{CH}$ and Collins FH (1996). Phylogeny of nearctic members of the Anopheles maculipennis species group derived from the D2 variable region of $28 S$ ribosomal RNA. Mol. Phylogenet. Evol. 6: 178-188.http://dx.doi.org/10.1006/mpev.1996.0070

Posada D and Crandall KA (2001). Intraspecific gene genealogies: trees grafting into networks. Trends Ecol. Evol. (Amst.) 16: 37-45.http://dx.doi.org/10.1016/S0169-5347(00)02026-7

Rogozin IB and Pavlov YI (2003). Theoretical analysis of mutation hotspots and their DNA sequence context specificity. Mutat. Res. 544: 65-85.http://dx.doi.org/10.1016/S1383-5742(03)00032-2

Schofield CJ and Galvão C (2009). Classification, evolution, and species groups within the Triatominae. Acta Trop. 110: 88100.http://dx.doi.org/10.1016/j.actatropica.2009.01.010

Templeton AR, Crandall KA and Sing CF (1992). A cladistic analysis of phenotypic associations with haplotypes inferred from restriction endonuclease mapping and DNA sequence data. III. Cladogram estimation. Genetics 132: 619-633. 